\title{
FRACTURE PENIS WITH BILATERAL CORPOREAL RUPTURE AND COMPLETED URETHRAL DISRUPTION: A CASE REPORT
}

Pulak Kumar Datta1 ${ }^{1}$ Asim Kumar Das ${ }^{2}$

\section{HOW TO CITE THIS ARTICLE:}

Pulak Kumar Datta, Asim Kumar Das. "Fracture Penis with Bilateral Corporeal Rupture and Completed Urethral Disruption: A Case Report". Journal of Evolution of Medical and Dental Sciences 2015; Vol. 4, Issue 08, January 26; Page: 1402-1404, DOI: 10.14260/jemds/2015/197

ABSTRACT: Fracture penis is a rare urological emergency. It commonly occurs during sexual intercourse. Unilateral injury of corpus cavernosa is common. We present a case of bilateral rupture of corpora cavernosa with complete rupture of urethra. It is very rare form of injury. Early surgery gives good result.

KEYWORDS: Penis, fracture, surgery.

INTRODUCTION: Fracture penis an uncommon urological emergency.[1] It is caused by trauma to erect penis. Sexual intercourse is commonest cause, but other forms of injury are also possible. Unilateral rupture of corpus cavernosum is common. Bilateral injury may also occur. We present a case of bilateral rupture of corpus cavernosa with complete rupture of urethra.

CASE HISTORY: A 40 year old man came to emergency with penile swelling, pain and retention of urine. Initially he gave history of trauma while rolling over in bed 12 hours ago. But on specifically enquiring, he revealed that it actually occurred during intercourse. He gave the history of popping sound followed by rapid detumescence, pain and swelling of penis. He was unable to void after that. On examination hematoma was found to spread up to root of penis. Rolling sign was felt bilaterally. Abdominal examination was unremarkable except full bladder was palpable. Patient was otherwise healthy. So he was taken to operating room.

A subcoronal circumferential incision was given. Penis was degloved. Tear was found in the tunica albuginea of the proximal part of penis. Both the corpora cavernosa was ruptured. Urethra was also found to be ruptured (Fig 1). Cavernosa was repaired in interrupted fashion with 3/0 vicryl. Urethra was repaired over no. 18 foley's catheter with 4/0 vicryl in interrupted fashion. Postoperative recovery was uneventful. He was discharged after 7 days. Foley's catheter was removed after 14 days. Patient was able to have painless erection, and normal voiding.

DISCUSSION: Fracture penis typically occurs with vigorous sexual intercourse. But it can happen with any type of blunt trauma to tumescent shaft of penis. It includes masturbation, falling out of bed with erect penis, forceful correction of chordee, disentangling an erect penis from garment etc.[2] Even it's a type of self-inflicted injury in Middle East countries.[2]

The patient's age among the reported cases ranged from 12 to 82 years. Most cases occur in the $4^{\text {th }}$ decade of life.

Tunica albuginea is one of the strongest fascia of the human body. ${ }^{[3]}$ But it thins out during erection. In flaccid state it is up to $2.4 \mathrm{~mm}$ thick; during erection it becomes as thin as. $25 \mathrm{~mm}$ to.5 $\mathrm{mm}$. So during erection penis becomes vulnerable to trauma. An intacorporal pressure of $1500 \mathrm{~mm}$ hg or more can tear tunica albuginea.[2,3,4] 
Unilateral injury is common, bilateral injury occurs in $2 \%$ to $10 \%$ cases..$^{[4,1]}$ Urethral injury is rarer occurring in $9 \%$ to $20 \%$ cases. ${ }^{[4]}$

Penile fracture is usually diagnosed by history and clinical examination. Classic features include an audible popping sound, rapid detumescence, pain, penile swelling. When buck's fascia remains intact the hematoma results in classical eggplant deformity. The defect at the fracture site is often palpable and has been described as the "rolling sign". [2] This represents a firm, mobile, tender mass, where the penile skin can be rolled over the blood clot. Other investigation like cavernosography and ultrasonography are done when history and clinical examination are not classical. MRI may be useful but not cost effective. ${ }^{[1]}$ The most common differential diagnosis of penile fracture is tear of dorsal artery and vein. When detected injured dorsal vein is ligated. ${ }^{[2]}$

Early surgery has excellent outcome. Subcoronal circumferential incision is the best described surgical approach. Other approach include penoscrotal, inguinoscrotal, suprapubic incision.[2,4]

Conservative management is also described. It includes splinting, cold compression, antiinflammatory analgesic.[2] However long term outcome of conservative management is not satisfactory. Significant complications like painful erection, erectile dysfunction arteriovenous fistula formation do occur.[2] So quick diagnosis and early surgical intervention is the key to success in fracture penis. Due to personal embarrassment there can be delay in presentation. 24 to $48 \mathrm{hrs}$ delay does not affect post-operative outcome, but further delay may be directly related to late postoperative complication.

\section{REFERENCES:}

1. Tiwary SK, Singh MK, Khanna R, Khanna AK. Penile fracture presenting as eggplant deformity; Kathmandu University Medical Journal (2006), Vol. 4, No. 2, Issue 14, 249-250.

2. Hoag NA, Hennessey K, So A. Penile fracture with bilateral corporeal rupture and complete urethral disruption: case report and literature review. Canadian Urological Association Journal 2011; 5(2): E23-E26. doi:10.5489/cuaj.10055.

3. Klemen Jagodič, Marko Erklavec, Igor Bizjak, Sandi Poteko, Helena Korošec Jagodič. A case of penile fracture with complete urethral disruption during sexual intercourse: a case report; Journal of Medical Case Reports 2007, 1:14 doi: 10.1186/1752-1947-1-14.

4. Srinivas B V, Vasan S S, Mohammed S. A case of penile fracture at the crura of the penis without urethral involvement: Rare entity. Indian J Urol 2012; 28:335-7.

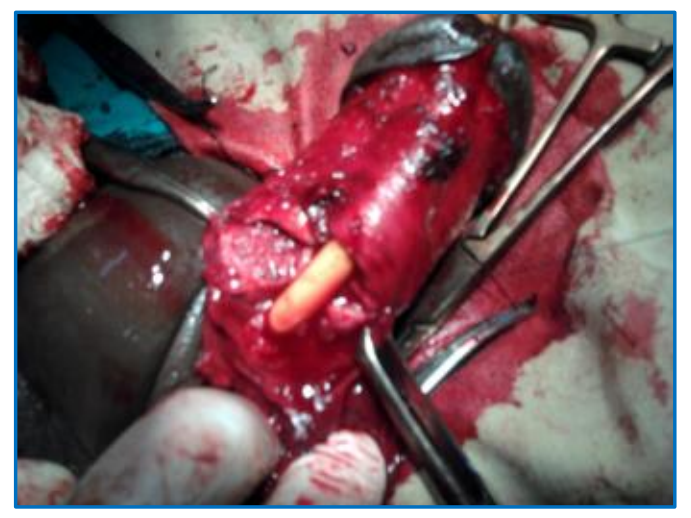

Fig. 1 


\section{AUTHORS:}

1. Pulak Kumar Dutta

2. Asim Kumar Das

\section{PARTICULARS OF CONTRIBUTORS:}

1. Assistant Professor, Department of General Surgery, Bardhaman Medical College, West Bengal.

2. RMO Clinical Tutor, Department of General Surgery, Bardhaman Medical College, West Bengal.

\section{NAME ADDRESS EMAIL ID OF THE} CORRESPONDING AUTHOR:

Dr. Pulak Kumar Datta, Ashiana Apartment, Bharsala More, Rampurhat, Birbhum-731224,

West Bengal.

E-mail:drpkdatta@gmail.com

Date of Submission: 04/01/2015. Date of Peer Review: 05/01/2015. Date of Acceptance: 16/01/2015. Date of Publishing: 24/01/2015. 